\title{
Rethinking Language Education in the US - A New Paradigm for Language Educators, Advocates, and Stakeholders
}

\author{
Kathleen Stein-Smith, PhD \\ Correspondence: Kathleen Stein-Smith, Fairleigh Dickinson University, Teaneck, NJ, USA.
}

Received: December 30, 2021

Accepted: January 30, $2022 \quad$ Online Published: February 4, 2022

doi:10.11114/ijce.v5i1.5477

URL: https://doi.org/10.11114/ijce.v5i1.5477

\begin{abstract}
In a globalized and interconnected world, language skills are more important than ever, yet US students lag behind those in many countries, and foreign language enrollment has declined, especially at the elementary and postsecondary levels. In order to build language skills in the US, it is necessary not only to embrace interdisciplinary collaborations, but also partnerships with communities. However, in addition to developing sustainable interest in languages and cultures and sustainable motivation for language learning, it is also necessary to address the issues of accessibility and affordability. Accessibility issues include availability of both in-person and online programs, and affordability includes fees and tuition at all levels, including after-school and weekend programs, and summer camps. Online learning and community partnerships, along with increased funding, play a vital role in make language learning accessible and affordable for all interested students. A language advocacy partnership among all stakeholders can play a significant role in resolving accessibility and affordability issues and making language learning available to all.
\end{abstract}

Keywords: language education, multilingualism, accessibility, affordability, motivation, purpose

\section{Introduction}

Communication is more important than ever in an interconnected and globalized world where numerous complex issues require ongoing multichannel communication. At the highest levels, multilingualism is considered essential, and many organizations - including the United Nations and the European Union -- have language policies encouraging the use of more than one language. The UN Sustainable Development Goals (SDGs) include Goal 17, Partnerships for Achieving the Goals, an implicit affirmation of the importance of language and languages. However, in the US, relatively few students study a language in school, often due to lack of opportunity (United Nations, n.d.; AMACAD, 2017).

In order for US students to compete successfully in the global marketplace, to act effectively as global citizens, and most importantly - to better understand and appreciate other cultures both globally and locally, it is essential to increase language skills. At present, while all students should have the opportunity to learn additional languages beginning at an early age, fewer than $20 \%$ of K-12 students study another language, and that number drops to $7.5 \%$ at the college and university level. In addition, language programs - especially in elementary and middle schools, and in colleges and universities, have diminished in number in recent years (AMACAD, 2017; MLA, 2019; American Councils, 2017).

It is essential to increase the availability and accessibility of language for all, and this means additional programs in our public schools and in higher education. It also means accessibility for all through affordable in-person and online programs. Partnerships with language stakeholders - in business and government, educational leaders, parents and communities, and learners themselves are needed in order to increase the number of language programs and to obtain funding for scholarships, grants, materials, and other needs. Teacher recruitment, training, and retention are also needed. At the present time, there is a shortage of qualified language teachers, and additional training and professional development opportunities and funding could be valuable retention tools (ACTFL, 2019; ACTFL, n.d.a; JNCL, 2021; Reed, 2021).

The challenge is to develop sustainable language learning from the earliest age, through traditional and immersion programs, to strengthen college and university programs, and to develop opportunities for learners of all ages through community-based and workplace programs. Online programs are a tool worth considering, as they can offer more affordable access to programs for learners of all ages and for those unable, for a variety of reasons, to study abroad or to travel to on-site programs. At the college level and for adult learners, online and hybrid programs are among the more flexible learning options that can support retention (Reed, 2021).

One aspect of language learning that may sometimes have been less considered is the joy of language learning. While the 
end result of being able to communicate effortlessly with others, to enjoy movies, music, and media, and to enjoy ordering a restaurant meal or negotiating an overseas encounter in another language while on vacation, the actual process of language learning may only be enjoyable for a relatively smaller number of learners. The inevitable tedious moments in a long process to proficiency and fluency can result in attrition - loss of interest and even abandonment of language learning, and the process itself has to be made as interesting and engaging as possible, which is not always easy and presents varying challenges in different settings.

It is also important to remember the role of the appeal of the culture of the target language, which also adds to appeal for the learner, and to maximize this appeal whenever possible (Jenkin, 2014). An example of this is the soft power of France, which also typically enjoys a high favorability rating among Americans, and generally ranks at or near the top in terms of soft power, or the appeal of a particular culture (Saad, 2016; Gray, 2017).

Another aspect of language learning that often results in loss of interest is a perception of lack of progress, when a lengthy period of learning is not visibly rewarded by conversational fluency. In addition to making the day-to-day learning pathway as interesting as possible, it is also essential to visibly demonstrate to the learner the progress being made through providing opportunities to use their language skills in settings where they can be appreciated by others and by the learners themselves.

Along with the need to make the process as enjoyable as possible and to provide tangible demonstrations of growing language skills, it is also necessary to explicitly address on a regular basis the reasons for language learning. Again, these may be as varied as the learner, but it is not enough to mention on the first day of class the benefits of language learning without taking the time to revisit the topic in different ways through the course in order to keep the goal - whatever it may be for each learner - clearly in sight during daily coursework.

\section{The Current Status of Languages in Education, Communities, and in Businesses and Organizations}

While in many countries virtually all students study one or more additional languages beginning in the earliest grades, in the US fewer than $20 \%$ of K-12 students study a foreign/world language (Devlin, 2018: American Councils, 2017). Perhaps even more importantly, few US public elementary schools offer a language program, and this means that most children, including those who may be disadvantaged, do not have the opportunity to learn an additional or heritage language at an early age and at the beginning of an extended period of continued learning (AMACAD, 2017). Issues facing our schools at present include not only lack of funding, but also lack of language requirements and enforcement of existing requirements, as well as a shortage of language teachers (MLA, 2014; JNCL, 2021; ECS, 2021).

At the other end of the spectrum, enrollment in courses in languages other than English at the postsecondary level has also diminished in recent years, with only $7.5 \%$ of students enrolled in a course in a language other than English, and resulting in a significant loss of language programs in US colleges and universities (MLA, 2019; Johnson, 2019). Issues facing our colleges and universities include limited pathways within the foreign language undergraduate majors (MLA, 2007). Career pathways, including pre-professional curriculum, experiential learning and internships, and interdisciplinary partnerships, need additional development.

In contrast to foreign language learning, the US is home to 70M who speak a language other than English in the home (Ryan, 2013). In addition to language programs in local schools, there are numerous community groups and communitybased organizations that support and promote language learning and use, which include The Franco-American Centre (FAC) in New Hampshire, the Council for the Development of the French Language in Louisiana (CODOFIL), and the Nous Foundation in Louisiana. Among the online initiatives in support of languages is the French-Canadian Legacy (FCL) Podcast and blog. It is interesting to note that, while the United States does not actually have an official language, many states do.

Beyond the profit sector, a wide range of international organizations require language skills, some of which have language policies, and some provide language training for their employees.

\section{Interdisciplinary Pathways to Strengthening Language Learning and Use in the United States}

The challenge is clear. The US needs foreign language skills, but most Americans speak only English, and relatively few US students study languages, or even have the opportunity to learn another language.

In order to effectively address this foreign language deficit, it is necessary for more US students of all ages to have the opportunity to learn another language.

Students need to have foreign language learning opportunities available to them from the earliest age, and these learning opportunities need to be available through our public schools, accessible to all children. In addition, foreign language learning needs to be affordable, with funding available for after-school, summer, and weekend language programs, and online and hybrid programs available for those unable to access onsite programs for a variety of reasons. 
Creation of new programs - either immersion or traditional -- especially in our public elementary schools, development of pre-professional programs especially at the college and university level, and the development of sustainable creative and career pathways are essential to foster and encourage language learning in the United States (AMACAD, 2017; MLA, 2015, 2019).

In terms of language use, both personal and professional, academic programs and community-based initiatives support language learning and use, with present and potential partnerships a natural synergy (Gagliano, 2019; Professional French Masters, n.d.; Villa Albertine, n.d.; French Language Job Fairs, n.d.).

While language educators and language advocates work every day to promote and defend language learning and use, it is also necessary to consider the perspectives and contributions from other disciplines, especially as they concern the benefits of language learning and use (ACTFL, n.d.; Fox, 2011; Grosjean, 2019; Kharkhurin, 2012).

\section{Language Learning in the Classroom and Beyond - Affordability and Authenticity}

In the classroom, foreign language educators use a variety of strategies to encourage and maintain student engagement use of authentic language, cultural learning, interactive games and other activities, media in the target language, and direct interaction with mother-tongue speakers via videoconferencing, etc.

Learning materials should be chosen with care to enhance learning through appropriate level of difficulty, and access to additional learning and assessment materials online should be guaranteed. If/when cost is directly passed along to the student, affordability of the materials needs to be taken into consideration. In all cases, the availability of the technology needed by the learner at home to maximize the effectiveness of online learning settings and materials needs to be taken into consideration and addressed by the school. Open education resources (OER), freely available, need to be included in the selection of learning materials.

Beyond the classroom, students should be encouraged to use the language conversationally and in internships and experiential learning in local settings, when possible, through exploration of their personal and pre-professional interests through the target language and culture, and through field trips and travel.

\section{Strategies for Change - Motivation, Purpose, and Partnerships}

In order to build the language capacity needed in the US, it is necessary to address language learning and use from several perspectives. In real time, it is essential to strengthen and defend programs at risk or potentially at risk. Planning for the future, it is equally important to focus on why we learn languages - the full range of personal and professional benefits, and how to increase access and opportunity for all interested learners to learn additional languages (ACTFL, n.d.). These are areas that offer opportunities for collaboration for language stakeholders in education and beyond.

In terms of purpose and motivation, it is important to give learners the opportunities to consider their reasons for language learning, and to return to that conversation at regular intervals during the process of language learning that is lengthy and sometimes tedious by its very nature. It is equally important to allow sufficient time for this, as each learner's personal journey in language learning is unique. This sense of purpose, whether it is a course requirement or a desire to connect or re-connect with a loved one or a family heritage language and culture, or an interest in global citizenship, conversation on the place of language and languages in the life of the learner, the uses of language(s) can and should be explicitly addressed in language curriculum - through course content and assignments, experiential learning and internships, and curriculum design including multidisciplinary collaborations to respond to both the personal and pre-professional interests of students.

It is especially important to highlight the professional, personal, and societal significance of language skills and cultural knowledge in the lives of learners - the benefits of multilingualism, along with the role of language in careers, and the sheer joy of being able to communicate and to connect with others in their language rather than solely in our own (NAE, 2017; ACTFL, 2019). At the higher education level, it is essential to explicitly highlight the links between a humanities major and professional success and between the skills and knowledge of the major and those skills required in the prospective workplace (Mintz, 2021; Lazar, 2018).

It is also important to focus on keeping students interested once they are enrolled. While learning foreign languages can be a marathon, and this might be frustrating, there are many other ways and avenues to not only 1) increase learner engagement along the way, 2) appeal to the diverse and tech-native generation coming up in the pipeline, and 3) create more opportunities for positive use of new language and reinforcement cycles.

Interdisciplinary partnerships can play an important role at all levels, from the earliest opportunities, including experiential and pre-professional learning, to interdisciplinary and joint programs at the college and university level and partnerships between foreign languages and related disciplines and pre-professional areas (Professional French, n.d.).

Immersion programs are an important pathway to building language skills, providing the opportunity for heritage language 
learners to strengthen and protect their language skills and for new learners to become bilingual through over 3,600 immersion programs in the US alone. California, Texas, New York, Utah, and North Carolina account for $60 \%$ of immersion programs, with Spanish the overwhelming leader, followed by Chinese and French (American Councils, 2021).

Language learning materials, the textbooks and online learning platforms used in teaching and learning, also need to be accessible and affordable. All too often, students are enrolled in a course, but cannot afford the textbook and/or the online learning platform that accompanies it. This can jeopardize student success, especially when tests, exams, and other assessment materials are only available through a platform that a student may not be able to afford. Possible solutions include the use of open educational resources (OER), such as textbooks, supplemental learning materials, and even entire online courses, as well as other instructor-created materials.

Alternatives to traditional classroom instruction can include summer language intensive courses and camps held on campus or in public schools, in order to attract students who may have an over-full schedule during the academic or school year, but still want to continue or to begin language study.

\section{Multilingualism in a Global World - Myths, Realities, and Empowerment}

The ability to speak and use another language is not unusual. In fact, half of the world population is multilingual (Grosjean, 2010, 2020). However, US students often have the impression that multilingualism is unusual, and that English, the global lingua franca, is enough (British Council, 2013). In order to make bilingualism and multilingualism an accepted part of daily life, it is necessary to shatter the myths and to demonstrate the realities of multilingualism and language learning to demonstrate the benefits of multilingualism and the fact that multilingualism is not something exceptional, but rather part of our lives, empowering us in every way.

In addition to benefits of languages and language learning, it is necessary to highlight with students the empowerment that language learning can bring, enabling the person with needed language skills and cultural knowledge to achieve personal and professional goals, to access information, education, and media that would not otherwise be available, and to connect with a whole world of people who may speak limited English, or who may not speak English at all either in business, social, helping, humanitarian-aid-related and an infinite number of situations varying with each individual.

Language means individual empowerment in that it is driven by the values and sense of purpose of each learner in order to achieve specific goals ranging from self-actualization to tangible career gains.

\section{Next Steps in Language Learning}

Language educators, advocates, and stakeholders need to work together to make language learning and language use part of the public conversation - through writing, research, speaking, and professional engagement, as well as through the media and social media,

It is equally necessary for all language stakeholders to actively participate in the ongoing dialogue between government and citizens to ensure that government officials at all levels are aware of the importance of languages and language learning,

As cost is often a barrier to language study - either to continuing learning a language beyond the required courses, or to beginning study of additional languages - it is essential to keep the financial cost and the opportunity cost of language learning as low as possible through scholarships, grants, partnerships, and support of community-based and online programs. In order to do this, partnerships with language stakeholders are essential. It is essential to remember that accessibility also means providing language learning opportunity to those who cannot attend traditional onsite or on campus classes, and this can include scholarships, online learning, as well as summer, weekend, evening, and short-term classes for those with disabilities and for non-traditional students with workplace and family responsibilities.

Once students are enrolled, it is also essential to bear in mind that not all of them have studied a language before, or that they have the study skills needed for successful language learning. Explicitly addressing both the joy of language learning and its role in fostering understanding, appreciation, and communication across cultures, as well as the mindset and habits of the students - the study skills - is needed for success. This can be done in the classroom, or through summer language boot camps, etc.

Once students are in the classroom, it is essential to provide authentic and relevant language learning materials appealing to a wide range of interests. Language textbooks and their associated language learning platforms can be both costly and daunting to inexperienced learners. Freely available online learning resources (OER) that provide the step-by-step information often needed by the new or inexperienced learners are essential in supporting students' success for all. It is also to provide an array of curricular offerings likely to appeal to the wide range of student interests and pre-professional needs and aspirations. We can learn from language education in other countries where an early start, teacher training, technology, language and educational policy, assessment, requirements, heritage languages, and - perhaps most 
importantly - leadership among language educators and supporters can bring about positive change (Pufahl, I., Rhodes, N.C, \& Christian, D., 2001). It is essential to consistently reward effort by ensuring and recognizing incremental wins in language learning.

Beyond the classroom, language educators, stakeholders, and supporters need to develop opportunities for students to use their additional language and to clearly see its value in their personal and professional lives, through social and creative activities, as well as through experiential learning, internships, and international education and study abroad, both on campus and online.

\section{The Nature and Role of Advocacy - In the Classroom and Beyond}

Advocacy "means persuading people who matter to care about your issue," and this explains the role and mission of language advocates. In order to accomplish this, language advocates need to focus on "getting listened to, being at the table when decisions are made, being heard by people who make decisions (Daly, 2011).

This role as a language advocate, whether for the language educator or stakeholder, involves leadership and offers opportunities for leadership, a "process whereby an individual influences a group of individuals to achieve a common goal (Northouse, 2013).

Language educators and a wide array of language stakeholders have a critical role to play in strengthening and building language learning and in launching a resurgence of language learning in the US.

First and foremost, we need to increase availability of and access to language learning. In addition, we need to highlight the real-life benefits and uses of language skills in our communities, both local and global, in all aspects of life, as well as the cognitive and other benefits within the individual, most importantly, the sheer joy of language use in interpersonal communication and in conversations at home, in the neighborhood, and in all our conversations across cultures, whether in a transnational team, an international organization, or while on vacation.

Requirements are another area where advocacy can play an important role, working to increase language learning requirements and to enforce those that already exist. At the college and university level, this applies to both entrance and degree requirements, where over-reliance on waivers, the opportunity cost of choosing a language course over a major course, and the sheer financial cost of each college credit are among the challenges. At the state level, advocacy can address high school graduation requirements, which vary widely among states, and the lack of specificity concerning languages in many state requirements (Lusin, 2014; ECS, 2021).

Advocates can also work to increase funding for language study, working with community and philanthropic partners to provide scholarships and other support for language learners.

\section{Current Trends and Future Directions}

While the challenges already facing language education have been exacerbated by the COVID pandemic, there are many positive indicators as well. In contrast to declining opportunity at the elementary and middle school level and declining enrollments at the postsecondary level, immersion programs are increasing, as are opportunities for online learning.

Beyond COVID, it is important to consider the increasing numbers of US students choosing to study abroad, and the growing emphasis on communication across cultures demonstrated in the United Nations Sustainable Development Goals (SDGs), especially in Goal 17, Partnerships. Rather than lack of interest and motivation, access and opportunity have become primary issues for language stakeholders, supporters, and advocates, with increased funding for language learning in public schools and beyond, both in person and online/hybrid education. In addition, it is essential to support community initiatives to bring language and cultural learning to heritage speakers and other interested participants both through in person and hybrid/online options, which also work to bring the best in teaching and support to all learners. (Reed, 2021).

\section{Conclusions - Access, Affordability, and Advocacy}

In a globalized and interconnected world and an increasingly multilingual US, it is more important than ever for all interested learners to have the opportunity to learn additional languages. In order for this to happen, we need to support language learning in our schools and in our communities, through our schools and institutions of higher education via the traditional classroom and online learning. It is equally important for us to support families and communities of heritage language speakers as they work to safeguard and preserve their heritage languages for their children and future generations.

The data and research are there, as is the heartfelt need for support to heritage language learning, support, and reacquisition. All that is needed now is strategy and action in order to operationalize cultural intelligence (CQ) in the US (Livermore, Ang, \& Van Dyne, 2015). The goal is to develop bilingual and bicultural individuals, not only fluent in more than one language, but also able to effectively understand and interact across cultures within a context of authentic intercultural conversations. 
Language skills and the cultural knowledge that is generally part of the language learning process are a wonderful tool to increase interest in, and understanding and appreciation of, other cultures. They are a gateway to a better understanding and appreciation of our personal family heritage and identity, and to the other languages that are part of our US history and identity and are the languages of our neighbors and communities. Just as importantly, they provide a window on other cultures around the world, and a tool to interact with and to help others in working to make the world a better place and in effectively addressing complex global issues.

\section{Concluding Thought - The Joy and Empowerment of Languages}

The key is making better known the sheer joy of language learning, not as difficult as often envisioned, which is sometimes lost in the busy lives of students, and the role that languages can play in our lives, enabling us to have conversations and build relationships with others. The next key step is making this opportunity available and accessible to all our children and to all interested language learners.

\section{References}

American Academy of Arts \& Sciences. (AMACAD). (2017). America's Languages: Investing in Language Education for the $21^{\text {st }}$ Century. https://www.amacad.org/publication/americas-languages

American Council on the Teaching of Foreign Languages, (ACTFL). (2019). Making Languages Our Business.: Addressing Foreign Language Demand among U.S. Employers. https://www.leadwithlanguages.org/languageadvocacy/publications/

American Council on the Teaching of Foreign Languages. (ACTFL). (n.d,). Benefits of Language Learning. https://www.actfl.org/resources/guiding-principles-language-learning/benefits-language-learning

American Council on the Teaching of Foreign Languages. (ACTFL). (n.d.a.) Educators Rising 2.0. https://www.actfl.org/advocacy/educators-rising

American Councils on International Education. (2017). The National K-12 Foreign Language Enrollment Study Report. https://www.americancouncils.org/news/announcements/new-report-world-language-study-us-k-12-schools

American Councils on International Education. (2021). ARC Completes National Canvass of Dual Language Immersion Programs in U.S. Public Schools.

https://www.americancouncils.org/news/announcements-featured-content/arc-completes-national-canvass-duallanguage-immersion-programs

British Council, (2013). The English Effect. https://www.britishcouncil.org/research-policy-insight/policy-reports/the-english-effect

Daly, J.A. (2011). Advocacy: Championing Ideas and Influencing Others. New Haven: Yale.

Devlin, K. (2018). Most European students are learning a foreign language in school while Americans lag. https://www.pewresearch.org/fact-tank/2018/08/06/most-european-students-are-learning-a-foreign-language-inschool-while-americans-lag/

Education Commission of the States. (ECS). (2021). High School Graduation Requirements: State Profiles. https://www.ecs.org/high-school-graduation-requirements-state-profiles/

Fox, K. (2011). Ellen Bialystok: Bilingual Brains are more healthy. https://www.theguardian.com/technology/2011/jun/12/ellen-bialystok-bilingual-brains-more-

healthy\#: :text=Ellen\%20Bialystok\%20is\%20a,delay\%20symptoms\%20of\%20Alzheimer's\%20disease.

Gagliano, (2019). Lafayette area businesses encouraged to just say 'oui' to keeping French language alive. https://www.theadvocate.com/acadiana/news/article_b96e8628-4db4-11e9-b987-8f521cb8f779.html

Gray, A. (2017). France becomes the world No 1 for soft power.

https://www.weforum.org/agenda/2017/07/france-new-world-leader-in-soft-power/

Grosjean, F. (2010, 2020), Bilingualism's Best Kept Secret. https://www.psychologytoday.com/us/blog/life-bilingual/201011/bilingualisms-best-kept-secret

Grosjean, F. (2019). A Journey in Languages and Cultures: The Life of a Bicultural Bilingual. Oxford.

Jenkin, M. (2014). What makes a language attractive - its sound, national identity or familiarity? https://www.theguardian.com/education/2014/jul/17/what-makes-a-language-attractive

Johnson, S. (2019). Colleges Lose a 'Stunning' 651 Foreign-Language Programs in 3 Years. https://www.chronicle.com/article/colleges-lose-a-stunning-651-foreign-language-programs-in-3years/\#: :text=Abroad\%20at\%20Home-,Colleges\%20Lose\%20a\%20'Stunning'\%20651\%20Foreign\%2D,Languag e\%20Programs $\% 20$ in $\% 203 \% 20$ Years\&text=The $\% 20$ new $\% 20$ data $\% 2$ C $\% 20$ which $\% 20$ the,program $\% 20$ from $\% 2020$ 
$09 \% 20$ to $\% 202013$

Joint National Committee for Languages (JNCL). (2021). JNCL Hosts Congressional Briefing Calling Attention to National Language Educator Shortage.

https://www.languagepolicy.org/post/jncl-hosts-congressional-briefing-calling-attention-to-national-languageeducator-shortage

Kharkhurin, A. V. (2012). Multilingualism and Creativity. Multilingualism Matters.

Lazar, M. (2018). The Bilingual Advantage in the Global Workplace. https:/www.languagemagazine.com/2018/06/07/the-bilingual-advantage-in-the-global-workplace/

Livermore, D., Ang, S., \& Van Dyne, L. (2015). Leading with Cultural Intelligence: The Real Secret of Success. NY: AMACOM.

Lusin, N. (2014). The MLA Survey of Postsecondary Entrance and Degree Requirements for Languages Other Than English, 2009-10.

https://www.mla.org/Resources/Research/Surveys-Reports-and-Other-Documents/Teaching-Enrollments-andPrograms/The-MLA-Survey-of-Postsecondary-Entrance-and-Degree-Requirements-for-Languages-Other-ThanEnglish-2009-10

Mintz, S. (2021). Preparing Humanities Majors for Postgraduation Success. https:/www.insidehighered.com/blogs/higher-ed-gamma/preparing-humanities-majors-postgraduation-success

Modern Language Association. (2007). Foreign Languages and Higher Education: New Structures for a Strange World. https:/www.mla.org/Resources/Research/Surveys-Reports-and-Other-Documents/Teaching-Enrollments-andPrograms/Foreign-Languages-and-Higher-Education-New-Structures-for-a-Changed-World

Modern Language Association. (MLA). (2015). Data on Second Majors in Language and Literature, 2001-2013. https:/www.mla.org/Resources/Research/Surveys-Reports-and-Other-Documents/Teaching-Enrollments-andPrograms/Data-on-Second-Majors-in-Language-and-Literature-2001-13

Modern Language Association. (MLA). (2019). Enrollments in Languages Other Than English in United States Institutions of Higher Education. https://www.mla.org/Resources/Research/Surveys-Reports-and-Other-Documents/Teaching-Enrollments-andPrograms/Enrollments-in-Languages-Other-Than-English-in-United-States-Institutions-of-Higher-Education

New American Economy. (NAE). (2017). Not Lost in Translation: U.S. Jobs Market Needs Foreign Language Skills. https://research.newamericaneconomy.org/report/not-lost-in-translation-the-growing-importance-of-foreignlanguage-skills-in-the-u-s-job-market/

Northouse, P. G. (2013). Leadership: Theory and Practice. $6^{\text {th }}$ ed. Los Angeles: SAGE.

Professional French Masters Program at the University of Wisconsin Madison. (n.d.). https://pfmp.wisc.edu/

Pufahl, I., Rhodes, N. C., \& Christian, D. (2001). What We Can Learn from Foreign Language Teaching in Other Countries. https://eric.ed.gov/?id=ED456671

Reed, M. (2021). Hybrid Schedules as Retention Tools. https:/www.insidehighered.com/blogs/confessions-community-college-dean/hybrid-schedules-retention-tools

Ryan, C. (2013). Language Use in the United States: 2011. https://www.census.gov/library/publications/2013/acs/acs-22.html

Saad, L. (2016). France's Favorable Rating in U.S. Zooms to 87\%, a New High. https://news.gallup.com/poll/189602/france-favorable-rating-zooms-new-high.aspx

United Nations. (n.d.) The 17 Goals. https://sdgs.un.org/goals

Villa Albertine. (n.d.) https://frenchculture.org/books-and-ideas/13522-villa-albertine

\section{Copyrights}

Copyright for this article is retained by the author(s), with first publication rights granted to the journal.

This is an open-access article distributed under the terms and conditions of the Creative Commons Attribution license which permits unrestricted use, distribution, and reproduction in any medium, provided the original work is properly cited. 